\title{
Unmet needs in the management of schizophrenia
}

This article was published in the following Dove Press journal:

Neuropsychiatric Disease and Treatment

16 January 2014

Number of times this article has been viewed

Francisco Torres-González ${ }^{1,8}$ Inmaculada Ibanez-Casas ${ }^{1,8}$

Sandra Saldivia ${ }^{2,8}$

Dinarte Ballester ${ }^{3,8}$

Pamela Grandón ${ }^{4,8}$

Berta Moreno-Küstner 5

Miguel Xavier ${ }^{6,8}$

Manuel Gómez-Beneyto ${ }^{7,8}$

'Centro de Investigación Biomédica en Red de Salud Mental, University of Granada, Spain; ${ }^{2}$ Department of Psychiatry and Mental Health, Faculty of Medicine, University of Concepcion, Chile; ${ }^{3}$ Sistema de Saúde Mãe de Deus, Escola Superior de Saúde, Universidade do Vale do Rio dos Sinos, Brazil; ${ }^{4}$ Department of Psychology, Faculty of Social Sciences, University of Concepcion, Chile; ${ }^{5}$ Andalusian Psychosocial Research Group and Department of Personality, Assessment and Psychological Treatment, Faculty of Psychology, University of Malaga, Spain; ${ }^{6}$ Department of Mental Health, NOVA Medical School, Universidade Nova de Lisboa, Lisbon, Portugal; ${ }^{7}$ Centro de Investigación Biomédica en Red de Salud Mental, University of Valencia, Spain; ${ }^{8}$ Maristán Network, University of Granada, Granada, Spain

Correspondence: Francisco TorresGonzález

Avenida de Madrid, II, Granada, I8072, Spain

Tel +34663277774

Email ftorres@ugr.es
Abstract: Studies on unmet needs during the last decades have played a significant role in the development and dissemination of evidence-based community practices for persistent schizophrenia and other severe mental disorders. This review has thoroughly considered several blocks of unmet needs, which are frequently related to schizophrenic disorders. Those related to health have been the first block to be considered, in which authors have examined the frequent complications and comorbidities found in schizophrenia, such as substance abuse and dual diagnosis. A second block has been devoted to psychosocial and economic needs, especially within the field of recovery of the persistently mentally ill. Within this block, the effects of the current economic difficulties shown in recent literature have been considered as well. Because no patient is static, a third block has reviewed evolving needs according to the clinical staging model. The fourth block has been dedicated to integrated evidence-based interventions to improve the quality of life of persons with schizophrenia. Consideration of community care for those reluctant to maintain contact with mental health services has constituted the fifth block. Finally, authors have aggregated their own reflections regarding future trends. The number of psychosocial unmet needs is extensive. Vast research efforts will be needed to find appropriate ways to meet them, particularly regarding so-called existential needs, but many needs could be met only by applying existing evidence-based interventions. Reinforcing research on the implementation strategies and capacity building of professionals working in community settings might address this problem. The final aim should be based on the collaborative model of care, which rests on the performance of a case manager responsible for monitoring patient progress, providing assertive follow-up, teaching self-help strategies, and facilitating communication among the patient, family doctor, mental health specialist, and other specialists.

Keywords: schizophrenia, needs, unmet needs, severe mental disorders

\section{Introduction}

Since the middle of the last century, three successive approaches can be distinguished in the management of schizophrenia. In the 1960s, management was mainly focused on psychopathology, with little attention paid to contextual factors. Psychoanalysis, family therapy, rehabilitation, and the recently discovered neuroleptics were applied with more or less emphasis, depending on the theoretical affiliations of the clinicians. The needs of the patients and the methods of satisfying them were defined by the medical staff, and as a consequence, they were mainly of a clinical nature.

After deinstitutionalization, patients were faced with the difficulties of living in the community, and their psychiatric management had to take these difficulties into account. As mental health services increased in extension and diversity, management 
became more service-oriented. Facilitating access to housing, occupation, company, and social relationships was included in the management of schizophrenia, together with the previously identified clinical aspects.

In the last decades, the rising awareness of human rights and democratic sensibility in society at large has contributed to the empowerment of users of mental health services. Patients and carers both started to get involved in the identification of their individual needs. This resulted in the recognition of needs linked to human rights, such as the need for freedom and respect, and the so-called existential needs, such as the need for spirituality and the need to have a meaningful life.

Further refinement of the management of schizophrenia has been stimulated and supported by the development of instruments for the assessment of needs and the elaboration and diffusion of clinical practice guidelines (CPGs).

Management has become more specific under the influence of instruments developed for describing and quantifying psychopathological symptoms and signs, particularly in clinical research, such as questionnaires, clinical rating scales, and diagnostic interviews. The routine use of these measures is thought to improve decision-making and patient care. ${ }^{1}$ Recently, there has been growing interest in including patients' psychosocial performance and quality of life as essential parts of the aims for treatment, with a subsequent emergence of tools developed to measure them.

With the advent of community psychiatry, new tools to assess patients' psychosocial needs were developed. The Camberwell Assessment of Need is a good example of a tool developed to comprehensively evaluate several aspects of an individual's life and mental well-being. The views of staff members and service users are registered separately, allowing differences of opinion to be identified and a management plan to be negotiated. ${ }^{2}$

The prominence gained by users and their relatives in health care has led to their participation in the elaboration of new instruments, such as the Maristan Scale of Needs. ${ }^{3}$ This instrument is based on qualitative data obtained from users, carers, and professionals across several cultures and contains four factors: health needs, work and leisure needs, existential needs, and needs for support in daily life. ${ }^{3,4}$

In addition to their contribution to refining management and supporting decision-making, these instruments have helped to detect, define, and measure unmet needs and to identify new needs. Information about unmet needs may be obtained by directly asking the patient about them in the course of routine interviews; by making inferences from data, as well as from epidemiological surveys; or by using established needs assessment instruments. ${ }^{5}$

From a public health perspective, the unmet needs of persons with schizophrenia who have not made contact with health services are also a major problem. The treatment gap (TG) for schizophrenia across the world, including other nonaffective psychoses, has been estimated at $32.2 \%$ by the World Health Organization. ${ }^{6}$

CPGs gather recommendations, based on research evidence, on how to manage schizophrenia. More than $20 \mathrm{CPGs}$ from 18 countries have been published and are in use at the present time. ${ }^{7}$ Despite the fact that CPGs are widely known and contain viable and effective recommendations, actual implementation is often suboptimal. Discordance in CPG recommendations regarding psychosocial interventions ${ }^{8}$ may not help reduce observed practice variations in this area, but even in the area of psychopharmacology, evidence suggests that the management of schizophrenia is often poor. ${ }^{9}$ Inadequate implementation of CPGs may be caused by scarce resources, poor management of the available resources, and the effects of stigma. Multiple strategies have been proposed to improve CPG implementation. ${ }^{10}$

In summary, the management of schizophrenia at present is not supported by a finished and coherent body of scientific evidence but has, rather, developed during the last 50 years as a complex process of interactions among research, professional practice, service provision, user's experience, and mental health advocacy, and it is still evolving.

\section{Unmet health care needs: complications and comorbidities of schizophrenia}

Despite considerable advances in the process of care, schizophrenia and its related mental disorders are quite often associated with negative health outcomes. Plausible determinants include adverse effects of medication, drug abuse, smoking, inactivity, and disorganized patterns of nutrition and hygiene, which may facilitate the occurrence of serious comorbid medical problems such as obesity, metabolic syndrome, diabetes, and cardiovascular disorders, as well as chronic infective disorders. Substance abuse is the most common comorbidity among patients with schizophrenia and has a strong effect on the clinical picture (psychopathology), diagnosis, course of treatment, and prognosis.

Because of specific clinical characteristics (eg, delusions, negative symptoms, neurocognitive dysfunction, and disorganization), schizophrenia may impair the patient's capacity to identify symptoms of medical illness, report 
them to health professionals, and engage in treatment, in addition to complying with regular medical appointments plus prescribed medication.

Studies on the relationship between psychopathological symptoms in schizophrenia and quality of life have shown that negative symptoms and general psychopathology are the best predictors of quality of life in these patients. ${ }^{11}$ In contrast, the severity of negative symptoms and cognitive deficits are the best predictors of the objective dimension of quality of life. ${ }^{12}$ In addition, a higher severity of symptoms is related with a lower quality of life. ${ }^{13}$

\section{Somatic conditions}

The literature shows that there is a significant association between schizophrenia and several somatic disorders such as nutritional/metabolic disorders, cardiovascular conditions, and sexual dysfunctions, among others. Obesity, diabetes, and smoking are two times more frequently seen among patients with Severe Mental Disorder (SMD) than in the general population. ${ }^{14}$ These conditions may compromise medication compliance and the quality of life of patients with schizophrenia. Furthermore, life expectancy in schizophrenia is reduced, with an excess mortality that is two times higher than that in the general population, ${ }^{15,16}$ with cardiovascular diseases responsible for $50 \%$ of the excess mortality associated with schizophrenia diagnosis. ${ }^{17-22}$

Despite the contribution of several factors, the most important determinants of the poor somatic health of this population seem to be lifestyle-modifiable risk factors (smoking, alcohol, drugs, and lack of exercise), adverse effects of prescribed psychotropic medication, and poor access to goodquality mental health services. In fact, although psychiatrists are conscious of potential somatic problems in persons with schizophrenia, physical health assessment and management have been reported frequently as being scarce. ${ }^{23}$ This poor recognition of somatic conditions might be a result of reduced physical assessment skills, particularly after a long time of exclusive psychiatric practice.

Metabolic and nutritional problems are among the most reported findings not only in schizophrenia but also in other SMD. In schizophrenia, an increased likelihood risk for overweight, obesity, and abdominal obesity is present even in recently diagnosed and nonmedicated patients. ${ }^{24}$ Psychotropic medication is strongly associated with sexual dysfunctions ${ }^{25}$ and obesity, ${ }^{26}$ particularly in patients with significant negative symptoms, reduced social interaction, and disorganized behavior. Both conditions limit patients' everyday interpersonal relationships and frequently become their reason to reject medication. Although most antipsychotics may cause overweight, the risk seems greater for clozapine and olanzapine and smaller for aripiprazole and ziprasidone, with quetiapine and risperidone showing an intermediate risk profile. ${ }^{27,28}$ Mood stabilizers, such as lithium and valproate, and several antidepressants, particularly the tricyclic antidepressants, are also associated with a significant risk for obesity in schizophrenic patients. ${ }^{29}$

Patients with schizophrenia present with an excessive risk for metabolic syndrome (MS). ${ }^{30,31}$ Obesity and insulin resistance are core components of MS, together with hypertension, elevated triglycerides, and established determinants of diabetes. MS is strongly associated with increased mortality because of cardiovascular risk and might be present in almost half of the psychotic patients even 20 years after their first psychotic episode. ${ }^{32}$ Patients prescribed with secondgeneration antipsychotics show a higher incidence rate of MS than patients treated with first-generation antipsychotics. ${ }^{33}$ Despite this evidence, metabolic screening and monitoring are still limited, even in developed countries with effective health systems. ${ }^{34}$

Regarding type 2 diabetes, the prevalence of this illness in patients with schizophrenia is five times higher compared with in the general population, with a significant association with clozapine and olanzapine. Moreover, the TG of diabetes among schizophrenic patients remains quite high, reaching nontreatment rates around $40 \%$ in large-scale multicentric studies. ${ }^{35,36}$ The elevated prevalence of these metabolic problems may explain why the death rate from cardiovascular disorders in schizophrenic patients has not declined in recent years in developed countries, as it has in the general population, and stands as the first cause of mortality among patients with SMD. ${ }^{18,37}$ Patients with schizophrenia and other SMD are at greater risk of coronary heart diseases, ${ }^{19}$ stroke,${ }^{38}$ ventricular arrhythmias, ${ }^{39}$ and sudden death. ${ }^{40}$ Given that the excess of cardiovascular mortality is, at least partially, a result of modifiable risk factors (lack of exercise, obesity, smoking), there is a need to improve the access of schizophrenic patients to primary care facilities, where these issues can be evaluated and monitored first-hand.

In addition to metabolic and cardiovascular diseases, particular attention should also be given to other conditions frequently associated with poor physical outcomes in schizophrenia. For instance, in places where institutionalization remains the principal model of care, infections such as pneumonia and tuberculosis are still more prevalent in the institutionalized population than in noninstitutionalized populations. ${ }^{41,42}$ Heavy smoking, a strong risk factor for 
respiratory disorders, is much more common among psychiatric patients diagnosed with schizophrenia, particularly in long-term institutionalized patients, than in the general population ( $80 \%$ versus $20 \%$ in the adult population). ${ }^{43}$ Restoration of nicotine function, amelioration of unwanted dopamine blockade adverse effects, and improvement of cognitive and negative symptoms have been reported as possible causes for this finding, according to neurobiological research findings. ${ }^{43}$

In addition, considerable risk for the occurrence of diseases caused by viral infections, such as HIV (estimated to be $4 \%-23 \%),{ }^{26}$ hepatitis $\mathrm{B}$, and hepatitis $\mathrm{C}$, which is often related to intravenous drug abuse and unprotected sexual activity, has been systematically reported in schizophrenic patients. ${ }^{44}$

Although schizophrenia has been associated in several well-conducted studies with a decreased risk for cancer even after controlling for smoking, there are yet some conflicting results, and the subject is not closed. ${ }^{45}$ Possible sources of bias are the decreased access of psychotic patients to general medical services, the lower rate of autopsies among those patients, and the poor quality of some mental health case registers. ${ }^{46}$ More important from an organizational perspective, a large-scale study conducted in Australia showed that despite the lower incidence of neoplasm in schizophrenia patients, mortality resulting from cancer was increased (39\% higher in men and $24 \%$ higher in women; range, $17 \%-32 \%$ ) when compared with the general population, suggesting once again an unmet need in the access of those patients to medical services. ${ }^{47}$

Hyperprolactinemia, a common adverse effect of firstgeneration antipsychotics, has also been associated with breast cancer, osteoporosis, and hypogonadism, but the results are contradictory. ${ }^{48}$

\section{Substance abuse and dual diagnosis}

According to recent data, only $12.4 \%$ of American adults with dual diagnosis receive both mental health and substance abuse treatment. ${ }^{49}$ Comorbidity may be a result of several factors, probably in association. Mental disorders may predispose to the onset of substance use disorders in situations such as disinhibition, mood swings, overwhelming anxiety, and the adverse effects of medication. In contrast, substance use disorders may lead to the onset and maintenance of mental disorders through biological mechanisms such as heavy cannabis use during adolescence or comorbid panic and cocaine abuse resulting from brain kindling. Finally, common genetic and environmental causes should not be disregarded, as they may share similar physiopathological processes leading to an increased lifetime risk for comorbidity.

Epidemiological estimates of dual diagnosis may change with the definition criteria, the ability of mental health professionals to detect the problem, and the tools used to measure the disorders. Taking into account these methodological limitations, prevalence rates are still very substantial.

In the National Comorbidity Survey, $51.4 \%$ of respondents with a lifetime diagnosis of substance abuse disorder (including alcohol and drugs) also met criteria for at least another lifetime mental health disorder, with an odds ratio of 2.4. ${ }^{50}$ Other studies conducted in different places and settings also show high prevalence rates of comorbidity, ranging between $37 \%$ and $53 \%$, both in community surveys and clinical samples. ${ }^{51}$ Conversely, up to $66 \%$ of patients with schizophrenia meet criteria for at least a single substancerelated disorder in their lifetime. ${ }^{51}$

There is growing evidence that patients with a dual diagnosis do not respond well to conventional psychiatric treatment, creating demand for a new approach from a different perspective..$^{52}$ In fact, particular attention has to be given to the characteristically greater clinical severity, the greater exposure to environmental risk factors, the potential abuse of currently used pharmacological agents, and the lack of specific training of mental health professionals in dealing with this population. The shortage of trained clinicians as well as the widespread scarcity of specialized facilities offering integrated programs, even in developed countries, is a strong determinant of the high level of unmet needs for care in this area. ${ }^{53}$

\section{Other psychiatric comorbidities}

Psychiatric comorbidities are much more common among patients with schizophrenia than what would be expected by chance alone. ${ }^{54}$ Anxiety and depressive symptoms are seen quite frequently during the course of illness, with an estimated prevalence of $15 \%$ for panic disorder, $29 \%$ for posttraumatic stress disorder, and 23\% for obsessive-compulsive disorder. Surveys estimated that depression occurs in $50 \%$ of patients with schizophrenia, both during and after the emergence of florid psychotic symptoms..$^{55}$ In addition, depression reduces quality of life in schizophrenic patients. ${ }^{56,57}$

A recent systematic review of suicide in schizophrenia ${ }^{58}$ reported that lifetime risk of suicide was approximately $5 \%$. Risk factors included young age, being male, being educated, prior suicide attempts, depressive symptoms, active hallucinations and delusions, substance abuse, and the presence of insight. According to this review, delivery of 
effective treatment was the only reliable protective factor for suicide.

As we have shown, there is scientific evidence that patients with schizophrenia require comprehensive care focused on both their mental and physical needs. ${ }^{22}$ However, these patients are not regularly examined to assess their physical condition and the possible organic effects of pharmacological treatments. It is only recently that specific assessment protocols have been established for the follow-up of obesity, sedentary lifestyle, and life habits in these patients. In addition, patients with schizophrenia have more difficulties getting access to primary care ${ }^{59}$ and are less likely treated for physical problems. ${ }^{60}$ In the absence of scientific evidence for specific interventions, the use of CPGs is recommended to mitigate cardiovascular risk in patients with schizophrenia. ${ }^{61}$

\section{Unmet psychosocial and economic needs}

Patients with schizophrenia usually present with difficulties in diverse areas of daily life: they are predominantly unemployed, single, and have a low educational level. ${ }^{62-64}$ They have also difficulties with housing, as the Team Assessment Psychiatric Services (TAPS) project described ${ }^{65}$ and current literature emphasizes, ${ }^{66}$ and their income depends on community aids. ${ }^{67} \mathrm{~A}$ high proportion of patients with schizophrenia have little or no social contact or friends, present with a high risk of isolation, and have difficulties getting involved in leisure activities. ${ }^{67}$

In general, unmet needs differ depending on the sociocultural environment. Results from the European Psychiatric Services: Inputs Linked to Outcomes and Needs (EPSILON) study comparing users' needs in five European cities showed that needs diverge in different contexts and that more unmet needs were found in big urban areas, ${ }^{68}$ where poverty, unemployment, and other social problems are more severe. ${ }^{69}$ Psychosocial needs were reported by users as the most unmet and included daily activities, company, and intimate relationships. ${ }^{70}$ Similar findings were found in studies with users from Nordic countries, where psychosocial needs were also the most unmet, particularly those related to social relationships, ${ }^{71}$ which were also the most related to patients' quality-of-life perception. ${ }^{72}$ Social contact is one of the main domains related to quality of life and is the area in which schizophrenia patients claim the most dissatisfaction. Moreover, frequency of contact with relatives or friends has been shown to be a predictor of quality of life. ${ }^{73}$ Inversely, stigmatization and social exclusion may negatively affect perceived quality of life in patients with schizophrenia. ${ }^{74}$
It has been proven that patients presenting with a higher quality of life show a better perception of family functioning, which confirms the importance of families as social and emotional support networks and agents in meeting individuals' needs. ${ }^{75}$ In a Spanish study, users identified as unmet those needs related to health and social services provision, including psychotic symptoms, house upkeep, food, and information. ${ }^{76}$ These results were similar to those presented in a study comparing patients' needs in five European and Latin American countries, where Argentinean patients identified more needs related to health care, probably because of the fragmentation of their health system and their dependence on psychiatric hospitals. ${ }^{3}$ In India, a study found that two-thirds of patients' needs were unmet, the most important of which were psychotic symptoms, psychological stress, information, and money. ${ }^{77}$

The organization and provision of care in health systems, together with life conditions in the cities, undoubtedly influence needs satisfaction. When these systems are less wealthy, instrumental and economic aspects become more important; when these needs are satisfied, patients give more weight to social relationships.

Unmet needs can be classified in different levels (eg, community or health services) and from different perspectives (eg, users, families, and health teams). Mojtabai and colleages ${ }^{78}$ pointed out that according to epidemiological studies in the United States, at least $40 \%$ of patients with schizophrenia continue living in the community without any type of treatment for long periods of time, even if they present with significant symptoms. The main barrier for access to services is stigma associated with mental illness. Thus, negative perceptions about mental illness in the users are related to a higher number of unmet needs and to negative attitudes toward medication. ${ }^{79}$ In contrast, there is another group of patients that uses health services but presents with scarce adherence to treatment. In both groups, unmet needs are estimated from the comparison between recommended treatments and service use patterns. ${ }^{78}$

Along these lines, it has been shown that users present with different needs, depending on the type of intervention they are receiving. Cleary and colleagues ${ }^{80}$ found that patients with SMD, both in inpatient and community settings, shared the same unmet needs (daily activities, company, and intimate relationships) but that these needs were greater among institutionalized patients. In contrast, it has been shown that patients using long-term services require promotion of independence, stability in housing, stability in social networks, consistency of care, and addressing the theme of loss. ${ }^{81}$ Apparently, the 
unmet needs of users attending community and rehabilitation services tend to increase and change over time, with psychosocial needs perceived as the most important. ${ }^{82}$ In a study comparing the needs of users under rehabilitation programs in two points in time, more unmet housing and money needs were found in the present compared with in data from $1998 .^{83}$ These results lead to the hypothesis that needs are also sensitive to sociocultural changes, which could limit its use in services comparing assessment. ${ }^{84}$

Most studies agree that users, relatives, and health staff differ on their perceived unmet needs. ${ }^{85,86} \mathrm{~A}$ recent study found that health personnel reported a greater number of unmet needs than users. ${ }^{87}$ For the latter, unmet needs are mainly focused in the areas of social, personal, and intimate relationships.

In contrast, unmet needs also depend on the vital cycle stage and, thus, on the illness stage the patients are in. In older adults, most unmet needs are focused in the psychosocial and general health care areas, ${ }^{88}$ and the psychosocial and social areas are less covered than the environmental and physical areas. ${ }^{89}$ However, studies on first-episode psychosis are scarce. In one of these few studies, young people reported that $20 \%$ of their needs were unmet. ${ }^{90}$

These data are alarming, as most social impairment in schizophrenia occurs at the beginning of the illness, between the second and the fifth year after onset. ${ }^{91}$ This is why treatment of first episodes emphasizes not only symptoms reduction but also prevention of social decline. In the only longitudinal study published so far on the needs of first-episode schizophrenia patients, results showed that daily activities, psychotic symptoms, psychological stress, and social integration were most frequently reported as unmet needs. In the follow-up, second-generation medication showed no effect on the course of unmet needs. ${ }^{92}$ Antipsychotic treatment alone was not sufficient to account for the psychosocial needs of patients. In spite of that, interventions are still focused on symptoms management, instead of on rehabilitation or on improving social and occupational functioning. ${ }^{78}$ In contrast, unmet needs have been associated with risk behaviors such as aggression ${ }^{93}$ and can predict suicide when unmet need is related to interpersonal contact. ${ }^{94}$

It is important to bear in mind that, conversely, quality of life is also influenced by sociodemographic factors such as unemployment, ${ }^{75,95}$ sex, or age. ${ }^{73}$ It also has been found that male and older patients present with a poorer quality of life. In addition, the gap in unemployment rates between individuals with and those without mental health problems is significantly widened by financial crisis. ${ }^{96}$ Recent evidence supports that mental health recovery services should include programs that address employment issues. ${ }^{97}$

\section{The clinical staging model}

In the last 15 years, a new diagnostic approach has been developed in an attempt to overcome the limitations of the current diagnostic system (lack of validity and therapeutic utility): the clinical staging model. ${ }^{98}$ According to this model, studying the course, extension, and pattern of illness over time provides a more useful diagnostic system for both clinical practice and research. This model is based on the idea of providing the earliest possible effective intervention that could prevent progression to more advanced stages, or even promote regression to an earlier stage, including total remission. ${ }^{98}$ The identification of early clinical symptoms is the focus of this model, which makes it especially useful for adolescents and young adults - those at the age when onset of psychotic disorders usually occurs. The rationale for this focus on early detection and intervention is the robust association between longer duration of untreated psychosis and poorer response to treatment both on a short- and longterm basis. ${ }^{99,100}$

According to the clinical staging model, psychotic disorders evolve through three initial stages: the ultra-high risk (UHR) stage, the first-episode psychosis (FEP) stage, and the critical period of early psychosis.

Criteria for the identification of individuals at high risk (UHR) include attenuated positive psychotic symptoms, brief self-limited psychotic symptoms, and family history of psychotic disorder. ${ }^{98}$ Using these criteria, around $40 \%$ of individuals identified as UHR presented with FEP within a 1-year follow-up, even after receiving needs-based psychosocial interventions..$^{98,101-105}$ Studies on different intervention approaches in the UHR stage of psychosis have come to the conclusion that first-line treatments in UHR patients must be mild, including psychosocial interventions such as cognitive-behavioral therapy (CBT) or supportive therapy, or supplementation with eicosapentaenoic acid. If necessary, pharmacological approaches could also be employed, with aripiprazole as the best candidate..$^{98}$

Once a full psychotic episode is detected, the patient enters the FEP stage. In this stage, the main objective is to obtain the patient's engagement in pharmacological and psychosocial treatments. Interventions in this stage are broadly described in the International Clinical Practice Guidelines for Early Psychosis, ${ }^{106}$ published in 2005, and were supported by the European First Episode Schizophrenia Trial (EUFEST) study $^{107}$, favoring second-generation antipsychotics as 
first-line therapy in FEP, given their better tolerability. The inability of medications to produce significant improvements in patients' functioning has produced an increased interest in psychosocial interventions such as the need to enhance social recovery, ${ }^{108}$ especially in the educational and vocational field. ${ }^{109,110}$ In addition, cognitive remediation is one of the focuses in this stage. ${ }^{111,112}$ In summary, in this stage, both effective psychosocial intervention and well-managed medication are fundamental to avoiding progression of the illness.

The critical period in early psychosis is defined as the first 2-5 years after the diagnosis of a psychotic disorder. This is a very important stage, as it coincides with major developmental challenges such as forming a stable identity, peer network, vocational training, and intimate relationships. ${ }^{98}$ Treatment in this stage is aimed at minimizing the risk for relapse and the disability associated with the disorder, as well as maximizing social and functional recovery. Moreover, interventions should also be focused on maximizing the chances of treatment engagement, continuity of care, appropriate lifestyle, family support, and vocational recovery and progress. This can be achieved through patients' engagement in combined pharmacological and psychosocial interventions. However, here we find a huge TG between what is needed and what is provided, even in most developed countries ${ }^{113,114}$ (see section on Community Care for those reluctant to maintain contact with mental health service).

Nowadays, mental health services, particularly those oriented toward rehabilitation, promote a recovery view of service. Recovery is an individual process implicating the development of a new meaning and purpose in life beyond the psychiatric illness. ${ }^{115}$ Needs assessment permits going further than recovery from an individual point of view, as it shows where intervention is more important not only from the patient's but also from the social environment's point of view. ${ }^{87}$ As a consequence, needs assessment can be considered an articulating tool between the patient and the social environment beyond the illness itself.

\section{Integrated evidence-based interventions to improve the quality of life of persons with schizophrenia}

Quality of life has been considered as a unified concept to assess the effect of illness on daily life of people with schizophrenia. ${ }^{116}$ The main dimensions to assess this construct include psychopathological state, physical health, sociodemographic factors, level of functioning for daily life activities, and social relationships, understood as interpersonal contacts and involvement in social and leisure activities. ${ }^{117-120}$
There is a general accord in considering that quality of life should reflect a person's well-being, both at the objective and subjective levels, and that it refers to general satisfaction with life. The literature on this issue has shown that patients with schizophrenia present with a lower quality of life compared with healthy people in the community. ${ }^{116}$

Although the treatment of patients with schizophrenia has been traditionally focused on symptoms, given that they are associated with hospitalization episodes, it is nowadays considered that this treatment must be more comprehensive and must allow integration of patients into their community. This is why quality of life has been considered to be a main target in the treatment of these patients. ${ }^{95}$

Although it is obvious that drugs alone are not enough for facing schizophrenia, most schizophrenic patients will need to be treated with antipsychotics. The sooner the patient is treated with antipsychotics after the onset of the disease, the better overall outcome. It is a severe risk for the patient if this worldwide-accepted axiom is forgotten and antipsychotics also become an unmet need.

Several evidence-based pharmacological and psychosocial interventions to alleviate symptoms and improve functioning and quality of life of persons with schizophrenia are also available. Some of these interventions have been put together in packs of integrated care, such as the Optimal Treatment Project ${ }^{121}$ and the Patient Outcomes Research Team (PORT) report, ${ }^{122}$ and their feasibility and cost-effectiveness have been proved in naturalistic studies.

A recent systematic review and meta-analysis comparing antipsychotic drugs with placebo on relapse prevention in schizophrenia concluded that sustained antipsychotic treatment of patients diagnosed with schizophrenia lowers their risk of relapse, especially when depot preparations were used and independent of whether the antipsychotic belonged to the classic or the new generation of drugs. Authors recommend further studies focused on outcomes of social participation and related to long-term mobility and mortality rates induced by these treatments. ${ }^{123}$

Another extensive (data for 43,049 participants) and recent meta-analysis shows a comparison of the efficacy and tolerability of 15 antipsychotic molecules. According to the results, all drugs were significantly more effective than placebo, and the different molecules differ clearly in adverse effects and prove "small but robust" differences regarding their efficacy. Moreover, the authors question the accepted hierarchy of first-generation and second-generation antipsychotics, finally recommending the use of the drug best adapted to the needs of the individual patients. ${ }^{124}$ With regard 
to this issue, in routine clinical practice it is advisable to follow the findings and recommendations of the thoroughly detailed PORT study on schizophrenia. ${ }^{122}$

Falloon and colleagues conducted a multisite, worldwide ( $>80$ centers), naturalistic study that should also be commented on. The authors designed an "Optimal Treatment" package including only evidence-based strategies, with the main components being minimally effective antipsychotic drug strategies targeted to change symptom profiles, education of patients and informal carers in stress management strategies, assertive case management, goal-oriented social and occupational skills training, and specific pharmacological and/or psychological strategies for residual or emerging symptoms. The authors used a nonrandomized sample and did not apply the common exclusion criteria (comorbidity, dual diagnosis, etc), so the sample represented only typical clinical cases. According to their results, the combination of pharmacological and psychosocial strategies that had previously proven efficacious in controlled trials can be applied in routine practice without additional resources. The authors maintain that integrated optimal pharmacotherapy and psychosocial treatment programs may play a major role in expediting recovery from psychotic disorders and also are cost-effective. ${ }^{121}$

A very recent contribution by Mueser and colleagues offers additional evidence and claims for the clinical integration of empirically supported psychosocial interventions for schizophrenia. ${ }^{125}$

\section{Respect for human rights of the mentally ill}

Since the early 1990s, most international bodies have shown an increasing interest in the dignity of, the empowerment of, and respect for the mentally ill. ${ }^{126,127}$ Undoubtedly, this is a result of the "lobby-like" action of growing user movements, but certainly it is also a result of the new, predominant fieldwork of therapists: the community. Users and professionals were becoming aware that they also have to face new challenges, including stigma and social needs, among many others.

Also in the 1990s, the World Psychiatric Association started an ambitious Global Program to Reduce Stigma, known as Open the Doors. ${ }^{128}$ However, the results did not support the utility of an antistigma campaign with a broad approach but, rather, suggested a more specific focus, such as perceived dangerousness. ${ }^{129}$ The profound association in people's imagination between dangerousness and mental disorder, especially schizophrenia, constitutes a strong reality reinforced by media, and the fight against that connection should not be eliminated from any plan for mental health action.

One of the most common risks of a person suffering from schizophrenia under community care is being admitted to a hospital because of his or her mental conditions. The mere fact of hospitalization is a risk in itself because of the added stigma, plus the frequent suffering of lowering self-esteem and loss of dignity perception when coerced into involuntary treatment. Moreover, mostly if admitted compulsory, patients may also suffer other means of coercion to restrain their movements, such as mechanical constraint, isolation, or administration of nontherapeutic aimed drugs.

All this was extensively considered in the European Evaluation of Coercion in Psychiatry and Harmonization of Best Clinical Practice (EUNOMIA) study, supported by the European Commission in 12 countries. ${ }^{130-132}$ For the purposes of this review, the EUNOMIA findings can be summarized as follows:

1. There is a great heterogeneity on legislation across Europe regarding required conditions and procedures for compulsory admission. ${ }^{131}$

2. In most countries, the conditions and procedures for applying other coercive means were not regulated. ${ }^{131}$

3. The mere voluntary hospitalization is not a harmless decision to the patient. Patients who feel coerced, even those who have been voluntarily admitted, may have a poorer prognosis than those involuntary admitted legally. ${ }^{133}$

4. Future studies should identify the factors in legislation and clinical practice, including important staff-patient interactions, that could lead to a more constructive cooperation of all parties involved. ${ }^{132}$

We could add that when some users were asked in focus groups (not published), none of the coercive measures were naive to the patients, and in some cases patients felt them as an attack on their dignity. This statement certainly needs more research, using an appropriate qualitative method if possible.

Restoring users' dignity and self-esteem through their progressive empowerment and autonomy should be part of any recovery program. Quite a few of the most recent documents of the international bodies and multinational agencies support this and offer similar recommendations toward the same aim. ${ }^{130,134,135}$ However, the need for a better coordination of the different strategies and plans of action launched by 
these international institutions to guarantee the commitment of their member countries is noticeable.

\section{Community care for those reluctant to maintain contact with mental health service}

For a long time it has been known that there are patients who show unmet needs of service contact or unmet needs of psychosocial contact and of pharmacological treatment. A worldwide figure of unmet needs or TG for SMD was $32 \%$, according to a World Health Organization report. ${ }^{6}$ In 20014, another World Health Organization European study ${ }^{136}$ showed that the TG of SMD living in the community ranged between $35.5 \%$ and $50.3 \%$, including in the most developed countries.

Lack of insight, past experiences, and prejudices against health services, among other reasons, make this group of people reluctant to maintain therapeutic links. They live in the community, and without adequate treatment, they are at risk of progressive health deterioration, forced reinstitutionalization, or even imprisonment. ${ }^{137,138}$

The first of the two previously mentioned World Health Organization reports ${ }^{6}$ proposed ten recommendations to address the TG:

1. Mental health treatment should be accessible in primary care.

2. Psychotropic drugs need to be readily available.

3. Care should be shifted away from institutions and toward community facilities.

4. The public should be educated about mental health.

5. Families, communities, and consumers should be involved in advocacy, policy-making, and forming self-help groups.

6. National mental health programs should be established.

7. The training of mental health professionals should be increased and improved.

8. Links with other governmental and nongovernmental institutions should be increased.

9. Mental health systems should be monitored, using quality indicators.

10. More support should be provided for research.

More recently, a systematic World Psychiatric Association survey of leaders of psychiatry was completed in almost 60 countries, examining strategies to reduce the TG. The authors concluded that "scaling up of mental health services can only be achieved effectively if three elements are in place: task shifting to non-specialist providers; an increase in the specialist mental health resources to provide effective and sustained supervision and support; and a decentralization of those specialized mental health resources."139

Mental health services policy makers have been concerned about TG over the last decades, and many attempts have been made to solve it. Case management, intensive case management, assertive community treatment, and assertive outreach are or have been the most common names used to refer to successive models of community care specifically oriented to satisfy the unmet needs of the SMD.

It has been long known that assertive outreach and intensive case management can reduce hospitalizations of patients who are frequent users of inpatient care and can reduce overall mental health care costs. In addition, greater fidelity to the models produced better outcomes. ${ }^{140,141}$ This has also been validated in rural areas. ${ }^{142}$

SMD is very frequently found in the excluded homeless population, making it more difficult to engage them in services care. It is then that assertive community treatment offers significant advantages in reducing homelessness and symptom severity in homeless people with SMD. ${ }^{143}$ The best outcomes for housing stability were found for programs that combined housing and support. ${ }^{144}$

These models of intensive care outreach services can have significant benefits in terms of patient outcomes and service use. Moreover, the implications of specific nursing programs provide a useful framework for evaluating the effect of these services. ${ }^{145}$

A recent Cochrane review found that intensive models of community care were more effective for several relevant outcomes of people with SMD. These not only reduced hospitalization and increased adherence to care but also improved social functioning, although the effect on psychopathology was not so clear. ${ }^{146}$

The effectiveness comparison of numerous attempts of available community models would be beyond the scope of the present revision. In summary, though, we could say there is a general accord on four basic criteria: the outreach team should be mobile instead of based at a mental health center; the team should have its own, full responsibility for care of a given bunch of clients; the caseload/staff member ratio should remain low; and the care at the client home should be part of the team routine.

Very recently, a Cochrane Systematic Review considered a new movement aimed at increasing the adherence of those patients with SMD who are reluctant to seek care. The review compared past or present users of mental health centers that 
were providing care versus professionals enrolled in case management. There were no significant differences between the two groups in clinical psychopathology, satisfaction, adherence to care, or withdrawing from the study, among other variables. Those receiving care from past or present users of mental health services used crisis and emergency services slightly less frequently than those receiving care from professional staff. Regarding care procedure, it was found that past or present users spent more face-to-face time with patients. The author invites others to further research this matter, reinforcing the methodological approach and changing the location in diverse settings, including low- and middle-income countries. ${ }^{147}$

\section{Reflections regarding future trends}

The number of psychosocial unmet needs is extensive. Vast research efforts will be needed to find appropriate ways to meet them, particularly regarding the so-called existential needs, but many could be met only by applying existing evidence-based interventions. Despite the general awareness of protocols, algorithms, and clinical practice guidelines, research findings are slow to reach into the daily management of schizophrenia, and many useful and cost-effective techniques are ignored in practice. ${ }^{148}$ Reinforcing research on implementation strategies and the capacity-building of professionals working in community settings might help address this problem.

Regarding unmet health needs, evidence-based organizational techniques for the management of chronic disorders could be applied extensively to severe mental disorders. ${ }^{149,150}$ The Collaborative Model of Care may facilitate early detection and therapy of somatic disorders and improve treatment compliance in people with schizophrenia. This model of care rests on the performance of a case manager responsible for monitoring patient progress, providing assertive follow-up, teaching self-help strategies, and facilitating communication between the patient, the family doctor, the mental health specialist, and other specialists.

There are also unmet needs brought about by the psychiatric interventions themselves. Antipsychotic medications, while improving positive symptoms, may cause a variety of adverse effects that seriously interfere with quality of life. Use of low dosages, and even discontinuation of these medications in judiciously selected cases, will help to alleviate this problem as well as improve long-term functioning. ${ }^{151}$

Serious damage to quality of life may also come from some psychosocial interventions. The use of coercive procedures such as compulsory admission, community orders, or simple leverage, whether clinically justified or not, can be extremely detrimental to the quality of life. What is more, authoritarian and stigmatizing attitudes of mental health professionals frequently act as a barrier for the identification of a patient's preferences and needs. The participation of users and relatives in the planning and evaluation of mental health services and the growing collaboration between users, families, and mental health workers are key factors in bringing about the necessary change in these attitudes and behaviors. The incorporation of users in providing formal care within statutory mental health services is another example of this collaboration. ${ }^{147}$

One major advance in approaching the management of schizophrenia comes from conceiving it as a neurodevelopmental disorder that progresses in identifiable stages. Each developmental stage, modulated by sex and the phases of the vital cycle, is associated with different medical and psychosocial needs, and hence requires different and specific interventions. ${ }^{152,153}$ In this context, management interests are presently being displaced from cognitive impairment and negative symptoms during the chronic phase to the early stages of development.

Another issue concerns social policy and the availability of community facilities to cover basic social needs. Quality of life is associated with employment, income, and housing stability. Unemployment, poverty, and housing instability are high among people with mental health problems, and even more so in times of economic recession. ${ }^{96}$ Social policies designed to cover these basic needs are a must if we want to avoid institutionalization and maintain the quality of life of people with schizophrenia. Along these lines, the preservation of the welfare state is critical. During the last decade, coinciding with the economic crisis and as a consequence of a tide of privatizations driven by neoliberal ideologies, some public health services in Europe are being dismantled. Advocacy for protecting the basic rights of persons with SMD is now more necessary than ever.

\section{Disclosure}

The authors report no conflicts of interest in this work.

\section{References}

1. Gilbody SM, House AO, Sheldon TA. Outcome measures and needs assessment tools for schizophrenia and related disorders. Cochrane Database Syst Rev. 2003;(1):CD003081.

2. Phelan M, Slade M, Thornicroft G, et al. The Camberwell Assessment of Need: the validity and reliability of an instrument to assess the needs of people with severe mental illness. Br J Psychiatry. 1995;167(5): 589-595

3. Saldivia S, Torres-González F, Runte-Geidel A, et al. Standardization of the MARISTAN scale to measure needs in people with schizophrenia and related psychoses. Int J Soc Psychiatry. Epub April 10, 2013. 
4. Torres-Gonzalez F, Runte-Geidel A, Antonioli C, et al. Standardised measures of needs, stigma and informal care in schizophrenia using a bottom-up, cross-cultural approach. Ment Health Fam Med. 2012; 9(2):125-134.

5. Joska J, Flisher AJ. The assessment of need for mental health services. Soc Psychiatry Psychiatr Epidemiol. 2005;40(7):529-539.

6. Kohn R, Saxena S, Levav I, Saraceno B. The treatment gap in mental health care. Bull World Health Organ. 2004;82(11):858-866.

7. Gaebel W, Riesbeck M, Wobrock T. Schizophrenia guidelines across the world: a selective review and comparison. Int Rev Psychiatry. 2011;23(4):379-387.

8. Gaebel W, Weinmann S, Sartorius N, Rutz W, McIntyre JS. Schizophrenia practice guidelines: international survey and comparison. Br J Psychiatry. 2005;187:248-255.

9. Harrington M, Lelliott P, Paton C, Okocha C, Duffet R, Sensky T. The results of a multi-centre audit of the prescribing of antipsychotic drugs for in-patients in the UK. Psychiatrist. 2002;26:414-418.

10. Rowlands P. The NICE schizophrenia guidelines: the challenge of implementation. Adv Psychiatric Treatment. 2004;10: 403-412.

11. Zahiruddin O, Salleh MR. Burden of care in schizophrenia: implication of psychopathology of the illness. Malaysian J Psych. 2005;13(2): 34-40.

12. Caqueo-Urízar A, Gutiérrez-Maldonado J, Ferrer-García M, Morales AU, Fernández-Dávila P. Typology of schizophrenic symptoms and quality of life in patients and their main caregivers in northern Chile. Int J Soc Psychiatry. 2013;59(1):93-100.

13. Rudnick A. The impact of coping on the relation between symptoms and quality of life in schizophrenia. Psychiatry. 2001;64(4): 304-308.

14. Daumit GL, Pratt LA, Crum RM, Powe NR, Ford DE. Characteristics of primary care visits for individuals with severe mental illness in a national sample. Gen Hosp Psychiatry. 2002;24(6):391-395.

15. Brown S, Kim M, Mitchell C, Inskip H. Twenty-five year mortality of a community cohort with schizophrenia. BrJ Psychiatry. 2010;196(2): $116-121$.

16. Marder SR, Essock SM, Miller AL, et al. Physical health monitoring of patients with schizophrenia. Am J Psychiatry. 2004;161(8): 1334-1349.

17. Kendrick T. Cardiovascular and respiratory risk factors and symptoms among general practice patients with long-term mental illness. $\mathrm{Br} J$ Psychiatry. 1996;169(6):733-739.

18. Lawrence DM, Holman CD, Jablensky AV, Hobbs MS. Death rate from ischaemic heart disease in Western Australian psychiatric patients 1980-1998. Br J Psychiatry. 2003;182:31-36.

19. Osborn DP, Levy G, Nazareth I, Petersen I, Islam A, King MB. Relative risk of cardiovascular and cancer mortality in people with severe mental illness from the United Kingdom's General Practice Rsearch Database. Arch Gen Psychiatry. 2007;64(2):242-249.

20. Osby U, Correia N, Brandt L, Ekbom A, Sparén P. Time trends in schizophrenia mortality in Stockholm county, Sweden: cohort study. BMJ. 2000;321(7259):483-484.

21. Phelan M, Stradins L, Morrison S. Physical health of people with severe mental illness. BMJ. 2001;322(7284):443-444.

22. von Hausswolff-Juhlin Y, Bjartveit M, Lindström E, Jones P. Schizophrenia and physical health problems. Acta Psychiatr Scand Suppl. 2009;(438):15-21.

23. Casey DE, Haupt DW, Newcomer JW, et al. Antipsychotic-induced weight gain and metabolic abnormalities: implications for increased mortality in patients with schizophrenia. J Clin Psychiatry. 2004; 65 Suppl 7:4-18.

24. Citrome L, Blonde L, Damatarca C. Metabolic issues in patients with severe mental illness. South Med J. 2005;98(7):714-720.

25. Baggaley M. Sexual dysfunction in schizophrenia: focus on recent evidence. Hum Psychopharmacol. 2008;23(3):201-209.

26. Lambert TJ, Velakoulis D, Pantelis C. Medical comorbidity in schizophrenia. Med J Aust. 2003;178 Suppl:S67-S70.
27. American Diabetes Association; American Psychiatric Association; American Association of Clinical Endocrinologists; North American Association for the Study of Obesity. Consensus development conference on antipsychotic drugs and obesity and diabetes. J Clin Psychiatry. 2004;65(2):267-272.

28. Jones PB, Barnes TR, Davies L, et al. Randomized controlled trial of the effect on Quality of Life of second- vs first-generation antipsychotic drugs in schizophrenia: Cost Utility of the Latest Antipsychotic Drugs in Schizophrenia Study (CUtLASS 1). Arch Gen Psychiatry. 2006;63(10):1079-1087.

29. Holt RI. Review: severe mental illness, antipsychotic drugs and the metabolic syndrome. Br J Diabetes Vascular Dis. 2006;6(5):199-204.

30. Meyer JM, Nasrallah HA. Medical Illness and Schizophrenia. Arlington, VA: American Psychiatric Publishing, Inc; 2009.

31. Newcomer JW. Antipsychotic medications: metabolic and cardiovascular risk. J Clin Psychiatry. 2007;68 Suppl 4:8-13.

32. De Hert M, van Winkel R, Van Eyck D, et al. Prevalence of diabetes, metabolic syndrome and metabolic abnormalities in schizophrenia over the course of the illness: a cross-sectional study. Clin Pract Epidemiol Ment Health. 2006;2:14.

33. De Hert M, Schreurs V, Sweers K, et al. Typical and atypical antipsychotics differentially affect long-term incidence rates of the metabolic syndrome in first-episode patients with schizophrenia: a retrospective chart review. Schizophr Res. 2008;101(1-3):295-303.

34. Morrato EH, Newcomer JW, Kamat S, Baser O, Harnett J, Cuffel B. Metabolic screening after the American Diabetes Association's consensus statement on antipsychotic drugs and diabetes. Diabetes Care. 2009;32(6):1037-1042.

35. Frayne SM, Halanych JH, Miller DR, et al. Disparities in diabetes care: impact of mental illness. Arch Intern Med. 2005;165(22): 2631-2638.

36. Nasrallah HA, Meyer JM, Goff DC, et al. Low rates of treatment for hypertension, dyslipidemia and diabetes in schizophrenia: data from the CATIE schizophrenia trial sample at baseline. Schizophr Res. 2006;86(1-3):15-22.

37. Osby U, Correia N, Brandt L, Ekbom A, Sparén P. Mortality and causes of death in schizophrenia in Stockholm county, Sweden. Schizophr Res. 2000;45(1-2):21-28.

38. Lin HC, Hsiao FH, Pfeiffer S, Hwang YT, Lee HC. An increased risk of stroke among young schizophrenia patients. Schizophr Res. 2008;101(1-3):234-241.

39. Glassman AH, Bigger JT Jr. Antipsychotic drugs: prolonged QTc interval, torsade de pointes, and sudden death. Am J Psychiatry. 2001; 158(11):1774-1782.

40. Appleby L, Thomas S, Ferrier N, Lewis G, Shaw J, Amos T. Sudden unexplained death in psychiatric in-patients. Br J Psychiatry. 2000;176: 405-406.

41. Copeland LA, Mortensen EM, Zeber JE, Pugh MJ, Restrepo MI, Dalack GW. Pulmonary disease among inpatient decedents: Impact of schizophrenia. Prog Neuropsychopharmacol Biol Psychiatry. 2007;31(3):720-726.

42. Lönnroth K, Jaramillo E, Williams B, Dye C, Raviglione M. Tuberculosis: the role of risk factors and social determinants. In: Blas E, Sivasankara Kurup A, editors. Equity, Social Determinants and Public Health Programmes. Geneva: World Health Organization; 2010:219-241.

43. Winterer G. Why do patients with schizophrenia smoke? Curr Opin Psychiatry. 2010;23(2):112-119.

44. Rosenberg SD, Goodman LA, Osher FC, et al. Prevalence of HIV, hepatitis B, and hepatitis $\mathrm{C}$ in people with severe mental illness. Am J Public Health. 2001;91(1):31-37.

45. Barak Y, Achiron A, Mandel M, Mirecki I, Aizenberg D. Reduced cancer incidence among patients with schizophrenia. Cancer. 2005; 104(12):2817-2821

46. Grinshpoon A, Barchana M, Ponizovsky A, et al. Cancer in schizophrenia: is the risk higher or lower? Schizophr Res. 2005;73(2-3): 333-341. 
47. Lawrence D, Holman CD, Jablensky AV, Threlfall TJ, Fuller SA. Excess cancer mortality in Western Australian psychiatric patients due to higher case fatality rates. Acta Psychiatr Scand. 2000;101(5):382-388.

48. DE Hert M, Correll CU, Bobes J, et al. Physical illness in patients with severe mental disorders. I. Prevalence, impact of medications and disparities in health care. World Psychiatry. 2011;10(1):52-77.

49. Substance Abuse and Mental Health Services Administration. Results from the 2011 National Survey on Drug use and Health: Summary of National Findings. Rockville, MD: Substance Abuse and Mental Health Services Administration; 2012.

50. Kessler RC. The epidemiology of dual diagnosis. Biol Psychiatry. 2004;56(10):730-737.

51. Tiet QQ, Mausbach B. Treatments for patients with dual diagnosis: a review. Alcohol Clin Exp Res. 2007;31(4):513-536.

52. Goldsmith RJ, Garlapati V. Behavioral interventions for dual-diagnosis patients. Psychiatr Clin North Am. 2004;27(4):709-725.

53. Clark RE, Mueser KT. Progress in research on dual disorders. $\mathrm{Br} J$ Psychiatry. 2003;183:377-378.

54. Buckley PF, Miller BJ, Lehrer DS, Castle DJ. Psychiatric comorbidities and schizophrenia. Schizophr Bull. 2009;35(2):383-402.

55. Siris SG. Depression in schizophrenia: perspective in the era of "Atypical" antipsychotic agents. Am J Psychiatry. 2000;157(9): 1379-1389.

56. Cohen CI, Vahia I, Reyes P, et al. Focus on geriatric psychiatry: schizophrenia in later life: clinical symptoms and social well-being. Psychiatr Serv. 2008;59(3):232-234.

57. Eack SM, Newhill CE. Psychiatric symptoms and quality of life in schizophrenia: a meta-analysis. Schizophr Bull. 2007;33(5):1225-1237.

58. Hor K, Taylor M. Suicide and schizophrenia: a systematic review of rates and risk factors. J Psychopharmacol. 2010;24(Suppl 4):81-90.

59. Lester H, Tritter JQ, Sorohan H. Patients' and health professionals' views on primary care for people with serious mental illness: focus group study. BMJ. 2005;330(7500):1122.

60. Roberts L, Roalfe A, Wilson S, Lester H. Physical health care of patients with schizophrenia in primary care: a comparative study. Fam Pract. 2007;24(1):34-40.

61. Gierisch JM, Nieuwsma JA, Bradford DW, et al. Interventions to Improve Cardiovascular Risk Factors in People with Serious Mental Illness. Rockville, MD: Agency for Healthcare Research and Quality; 2013.

62. Moreno-Küstner B, Mayoral F, Pérez O, et al. The Malaga schizophrenia case-register (RESMA): overview of methodology and patient cohort. Int J Soc Psychiatry. 2009;55(1):5-15.

63. Moreno-Küstner B, Mayoral F, Rivas F, et al. Factors associated with use of community mental health services by schizophrenia patients using multilevel analysis. BMC Health Serv Res. 2011;11:257.

64. Moreno B, Arroyo B, Torres-González F, de Dios Luna J, Cervilla J. Social predictors of out-patient mental health contact in schizophrenia patients. Soc Psychiatry Psychiatr Epidemiol. 2007;42(6):452-456.

65. Leff J, Trieman N, Knapp M, Hallam A. The TAPS project: a report on 13 years of research, 1985-1998. Psychiatic Bull. 2000;24:165-168.

66. Devon County Council. Accomodation and Support Joint Strategic Needs Assessment for Mental Health. Exeter: Devon County Council; 2010. Available from: http://www.devon.gov.uk/jsna_mh-2.pdf. Accessed June 12, 2013.

67. Ritsner MS, Gibel A. Quality of life impairment syndrome in schizophrenia. In: Ritsner MS, Awad AG, editors. Quality of Life Impairment in Schizophrenia, Mood and Anxiety Disorders. Houten, The Netherlands: Springer; 2007.

68. McCrone P, Leese M, Thornicroft G, et al. A comparison of needs of patients with schizophrenia in five European countries: the EPSILON Study. Acta Psychiatr Scand. 2001;103(5):370-379.

69. Najim H, McCrone P. The Camberwell Assessment of Need: comparison of assessments by staff and patients in an inner-city and a semi-rural community area. Psychiatric Bull. 2005;29:13-17.

70. Thornicroft G, Tansella M, Becker T, et al; EPSILON Study Group. The personal impact of schizophrenia in Europe. Schizophr Res. 2004;69(2-3):125-132.
71. Middelboe T, Mackeprang T, Hansson L, et al. The Nordic Study on schizophrenic patients living in the community. Subjective needs and perceived help. Eur Psychiatry. 2001;16(4):207-214.

72. Hansson L, Sandlund M, Bengtsson-Tops A, et al. The relationship of needs and quality of life in persons with schizophrenia living in the community. A Nordic multi-center study. Nord J Psychiatry. 2003;57(1):5-11.

73. Gaite L, Vázquez-Barquero JL, Borra C, et al; EPSILON Study Group. Quality of life in patients with schizophrenia in five European countries: the EPSILON study. Acta Psychiatr Scand. 2002;105(4): 283-292.

74. van der Plas AG, Hoek HW, van Hoeken D, Valencia E, van Hemert AM. Perceptions of quality of life and disability in homeless persons with schizophrenia and persons with schizophrenia living in non-institutional housing. Int J Soc Psychiatry. 2012;58(6): 629-634.

75. Caqueo Urízar A, Lemos Giráldez S. [Quality of life and family functioning in schizophrenia patients]. Psicothema. 2008;20(4):577-582. Spanish.

76. Ochoa S, Haro JM, Autonell J, Pendàs A, Teba F, Màrquez M; NEDES Group. Met and unmet needs of schizophrenia patients in a Spanish sample. Schizophr Bull. 2002;9(2):201-210.

77. Kulhara P, Avasthi A, Grover S, et al. Needs of Indian schizophrenia patients: an exploratory study from India. Soc Psychiatry Psychiatr Epidemiol. 2010;45(8):809-818.

78. Mojtabai R, Fochtmann L, Chang SW, Kotov R, Craig TJ, Bromet E. Unmet need for mental health care in schizophrenia: an overview of literature and new data from a first-admission study. Schizophr Bull. 2009;35(4):679-695.

79. Broadbent E, Kydd R, Sanders D, Vanderpyl J. Unmet needs and treatment seeking in high users of mental health services: role of illness perceptions. Aust N Z J Psychiatry. 2008;42(2):147-153.

80. Cleary M, Freeman A, Hunt GE, Walter G. Patient and carer perceptions of need and associations with care-giving burden in an integrated adult mental health service. Soc Psychiatry Psychiatr Epidemiol. 2006;41(3):208-214.

81. Chopra P, Herrman HE. The long-term outcomes and unmet needs of a cohort of former long-stay patients in Melbourne, Australia. Community Ment Health J. 2011;47(5):531-541.

82. Kallert TW, Leisse M, Winiecki P. Needs for care of chronic schizophrenic patients in long-term community treatment. Soc Psychiatry Psychiatr Epidemiol. 2004;39(5):386-396.

83. Killaspy H, Rambarran D, Bledin K. Mental health needs of clients of rehabilitation services: a survey in one Trust. $J$ Mental Health. 2008;17(2):207-218.

84. Wiersma D, van den Brink R, Wolters K, et al. Individual unmet needs for care: are they sensitive as outcome criterion for the effectiveness of mental health services interventions? Soc Psychiatry Psychiatr Epidemiol. 2009;44(4):317-324.

85. Grinshpoon A, Friger M, Orev E, et al. Relative perceptions of the needs of inpatients with schizophrenia and schizoaffective disorders. Isr J Psychiatry Relat Sci. 2008;45(3):201-209.

86. Korkeila J, Heikkilä J, Hansson L, Sørgaard KW, Vahlberg T, Karlsson H. Structure of needs among persons with schizophrenia. Soc Psychiatry Psychiatr Epidemiol. 2005;40(3):233-239.

87. Werner S. Needs assessment of individuals with serious mental illness: can it help in promoting recovery? Community Ment Health J. 2012;48(5):568-573.

88. Cummings SM, Cassie KM. Perceptions of biopsychosocial services needs among older adults with severe mental illness: met and unmet needs. Health Soc Work. 2008;33(2):133-143.

89. Meesters PD, Comijs HC, Dröes RM, et al. The care needs of elderly patients with schizophrenia spectrum disorders. Am J Geriatr Psychiatry. 2013;21(2):129-137.

90. Boeing L, Murray V, Pelosi A, McCabe R, Blackwood D, Wrate R. Adolescent-onset psychosis: prevalence, needs and service provision. Br J Psychiatry. 2007;190:18-26. 
91. an der Heiden W, Häfner H. The epidemiology of onset and course of schizophrenia. Eur Arch Psychiatry Clin Neurosci. 2000;250(6): 292-303.

92. Landolt K, Rössler W, Burns T, et al; EUFEST Study Group. Unmet needs in patients with first-episode schizophrenia: a longitudinal perspective. Psychol Med. 2012;42(7):1461-1473.

93. Martínez-Martín N, Fraguas D, García-Portilla MP, et al. Selfperceived needs are related to violent behavior among schizophrenia outpatients. J Nerv Ment Dis. 2011;199(9):666-671.

94. Tidemalm D, Elofsson S, Stefansson CG, Waern M, Runeson B. Predictors of suicide in a community-based cohort of individuals with severe mental disorder. Soc Psychiatry Psychiatr Epidemiol. 2005;40(8):595-600.

95. Adewuya AO, Makanjuola RO. Subjective quality of life of Nigerian schizophrenia patients: sociodemographic and clinical correlates. Acta Psychiatr Scand. 2009;120(2):160-164.

96. Evans-Lacko S, Knapp M, McCrone P, Thornicroft G, Mojtabai R. The mental health consequences of the recession: economic hardship and employment of people with mental health problems in 27 European countries. PLoS One. 2013;8(7):e69792.

97. Harvey SB, Henderson M, Lelliott P, Hotopf M. Mental health and employment: much work still to be done. Br J Psychiatry. 2009; 194(3):201-203.

98. McGorry PD. Staging in neuropsychiatry: a heuristic model for understanding, prevention and treatment. Neurotox Res. 2010;18(3-4): 244-255.

99. Marshall M, Lewis S, Lockwood A, Drake R, Jones P, Croudace T. Association between duration of untreated psychosis and outcome in cohorts of first-episode patients: a systematic review. Arch Gen Psychiatry. 2005;62(9):975-983.

100. Perkins DO, Gu H, Boteva K, Lieberman JA. Relationship between duration of untreated psychosis and outcome in first-episode schizophrenia: a critical review and meta-analysis. Am J Psychiatry. 2005;162(10):1785-1804.

101. Mason O, Startup M, Halpin S, Schall U, Conrad A, Carr V. Risk factors for transition to first episode psychosis among individuals with 'at-risk mental states'. Schizophr Res. 2004;71(2-3):227-237.

102. Miller TJ, McGlashan TH, Rosen JL, et al. Prospective diagnosis of the initial prodrome for schizophrenia based on the Structured Interview for Prodromal Syndromes: preliminary evidence of interrater reliability and predictive validity. Am J Psychiatry. 2002;159(5):863-865.

103. Riecher-Rössler A, Gschwandtner U, Aston J, et al. The Basel early-detection-of-psychosis (FEPSY)-study - design and preliminary results. Acta Psychiatr Scand. 2007;115(2):114-125.

104. Ruhrmann S, Schultze-Lutter F, Klosterkötter J. Early detection and intervention in the initial prodromal phase of schizophrenia. Pharmacopsychiatry. 2003;36 Suppl 3:S162-S167.

105. Yung AR, Phillips LJ, Yuen HP, et al. Psychosis prediction: 12-month follow up of a high-risk ("prodromal") group. Schizophr Res. 2003;60(1):21-32.

106. International Early Psychosis Association Writing Group. International clinical practice guidelines for early psychosis. $\mathrm{Br} J$ Psychiatry. 2005;187:s120-s124

107. Kahn RS, Fleischhacker WW, Boter H, et al; EUFEST study group. Effectiveness of antipsychotic drugs in first-episode schizophrenia and schizophreniform disorder: an open randomised clinical trial. Lancet. 2008;371(9618):1085-1097.

108. Fowler D, Hodgekins J, Painter M, et al. Cognitive behaviour therapy for improving social recovery in psychosis: a report from the ISREP MRC Trial Platform Study (Improving Social Recovery in Early Psychosis). Psychol Med. 2009;39(10):1627-1636.

109. Fraser R, Berger G, Killackey E, McGorry P. Emerging psychosis in young people - Part 3 - key issues for prolonged recovery. Aust Fam Physician. 2006;35(5):329-333.

110. Killackey E, Jackson HJ, McGorry PD. Vocational intervention in first-episode psychosis: individual placement and support $\mathrm{v}$ treatment as usual. Br J Psychiatry. 2008;193(2):114-120.
111. Eack SM, Greenwald DP, Hogarty SS, et al. Cognitive enhancement therapy for early-course schizophrenia: effects of a two-year randomized controlled trial. Psychiatr Serv. 2009;60(11):1468-1476.

112. Wykes T, Newton E, Landau S, Rice C, Thompson N, Frangou S. Cognitive remediation therapy (CRT) for young early onset patients with schizophrenia: an exploratory randomized controlled trial. Schizophr Res. 2007;94(1-3):221-230.

113. McGorry PD, Yung AR, Bechdolf A, Amminger P. Back to the future: predicting and reshaping the course of psychotic disorder. Arch Gen Psychiatry. 2008;65(1):25-27.

114. McGorry PD, Killackey E, Yung A. Early intervention in psychosis: concepts, evidence and future directions. World Psychiatry. 2008;7(3): 148-156.

115. Anthony WA. A recovery-oriented service system: setting some system level standards. Psychiatric Rehab J. 2000;24(2):159-168.

116. Pinikahana J, Hapell B, Hope J, Keks NA. Quality of life in schizophrenia: a review of the literature from 1995 to 2000. Int $J$ Mental Health Nurs. 2002;11:103-111.

117. Aki H, Tomotake M, Kaneda Y, et al. Subjective and objective quality of life, levels of life skills, and their clinical determinants in outpatients with schizophrenia. Psychiatry Res. 2008;158(1):19-25.

118. Cavieres A, Valdebenito M. Cognitive function and quality of life in schizophrenia. Revista Chilena Neuro-Psiquiatría. 2005;43:97-108.

119. Narvaez JM, Twamley EW, McKibbin CL, Heaton RK, Patterson TL. Subjective and objective quality of life in schizophrenia. Schizophr Res. 2008;98(1-3):201-208.

120. Yamauchi K, Aki H, Tomotake M, et al. Predictors of subjective and objective quality of life in outpatients with schizophrenia. Psychiatry Clin Neurosci. 2008;62(4):404-411.

121. Falloon IR, Montero I, Sungur M, et al; OTP Collaborative Group. Implementation of evidence-based treatment for schizophrenic disorders: two-year outcome of an international field trial of optimal treatment. World Psychiatry. 2004;3(2):104-109.

122. Kreyenbuhl J, Buchanan RW, Dickerson FB, Dixon LB; Schizophrenia Patient Outcomes Research Team (PORT). The Schizophrenia Patient Outcomes Research Team (PORT): updated treatment recommendations 2009. Schizophr Bull. 2010;36(1):94-103.

123. Leucht S, Tardy M, Komossa K, et al. Antipsychotic drugs versus placebo for relapse prevention in schizophrenia: a systematic review and meta-analysis. Lancet. 2012;379(9831):2063-2071.

124. Leucht S, Cipriani A, Spineli L, et al. Comparative efficacy and tolerability of 15 antipsychotic drugs in schizophrenia: a multipletreatments meta-analysis. Lancet. 2013;382(9896):951-962.

125. Mueser KT, Deavers F, Penn DL, Cassisi JE. Psychosocial treatments for schizophrenia. Annu Rev Clin Psychol. 2013;(9)465-497.

126. Latin America within the Local Health Systems, Pan-American Health Organization [PAHO]/World Health Organization [WHO], Venez. November 14, 1990.

127. United Nations. Principles for the protection of persons with mental illness and the improvement of mental health care, 46/119. New York: United Nations; 1991. Available from http://www.un.org/documents/ ga/res/46/a46r119.htm. Accessed May 23, 2013.

128. Rosen A, Walter G, Casey D, Hocking B. Combating psychiatric stigma: an overview of contemporary initiatives. Australasian Psychiatry. 2000;8(1):19-26.

129. Thompson AH, Stuart H, Bland RC, et al; WPA. World Psychiatric Association. Attitudes about schizophrenia from the pilot site of the WPA worldwide campaign against the stigma of schizophrenia. Soc Psychiatry Psychiatr Epidemiol. 2002;37(10):475-482.

130. Health and Consumer Protection Directorate-General EC. Improving the mental health of the population: Towards a strategy on mental health for the European Union. Brussels: European Commission; 2005. Available from: http://ec.europa.eu/health/ph_determinants/life_style/ mental/green_paper/mental_gp_en.pdf. Accessed May 14, 2013.

131. Kallert TW, Torres-Gonzalez F. Legislation on Coercive Mental Health Care in Europe. Legal Documents and Comparative Assessment of Twelve European Countries. Frankfurt am Main: Peter Lang; 2006. 
132. Raboch J, Kalisová L, Nawka A, et al. Use of coercive measures during involuntary hospitalization: findings from ten European countries. Psychiatr Serv. 2010;61(10):1012-1017.

133. Kallert TW, Katsakou C, Adamowski T, et al. Coerced hospital admission and symptom change - a prospective observational multi-centre study. PLoS One. 2011(6):e28191.

134. Pan American Health Organization. Supporting the Implementation of Mental Health Policies in the Americas: A Human Rights Law-Based Approach. Findings, Trends and Targets for Public Health Action. Washington, DC: PAHO; 2010.

135. World Health Organization. User empowerment in mental health - a statement by the WHO Regional Office for Europe. Copenhagen: World Health Organization; 2010.

136. Demyttenaere K, Bruffaerts R, Posada-Villa J, et al; WHO World Mental Health Survey Consortium. Prevalence, severity, and unmet need for treatment of mental disorders in the World Health Organization World Mental Health Surveys. JAMA. 2004;291(21):2581-2590.

137. Priebe S, Badesconyi A, Fioritti A, et al. Reinstitutionalisation in mental health care: comparison of data on service provision from six European countries. BMJ. 2005;330(7483):123-126.

138. Torres-Gonzales F. Trastornos psiquiátricos severos: criterios de calidad (con especial énfasis en el tratamiento asertivo comunitario). [Severe Psychiatric Disorders: quality criteria (with special emphasis in assertive community treatment)] Revista GPU. 2013;9(1):75-80. Spanish.

139. Patel V, Maj M, Flisher AJ, De Silva MJ, Koschorke M, Prince M; WPA Zonal and Member Society Representatives. Reducing the treatment gap for mental disorders: a WPA survey. World Psychiatry. 2010;9(3):169-176.

140. Quinlivan R, Hough R, Crowell A, Beach C, Hofstetter R, Kenworthy K. Service utilization and costs of care for severely mentally ill clients in an intensive case management program. Psychiatr Serv. 1995;46(4): 365-371.

141. Scott JE, Dixon LB. Assertive community treatment and case management for schizophrenia. Schizophr Bull. 1995;21(4):657-668.

142. Meyer PS, Morrissey JP. A comparison of assertive community treatment and intensive case management for patients in rural areas. Psychiatr Serv. 2007;58(1):121-127.

143. Coldwell CM, Bender WS. The effectiveness of assertive community treatment for homeless populations with severe mental illness: a metaanalysis. Am J Psychiatry. 2007;164(3):393-399.
144. Nelson G, Aubry T, Lafrance A. A review of the literature on the effectiveness of housing and support, assertive community treatment, and intensive case management interventions for persons with mental illness who have been homeless. Am J Orthopsychiatry. 2007;77(3): 350-361.

145. Endacott R, Eliott S, Chaboyer W. An integrative review and metasynthesis of the scope and impact of intensive care liaison and outreach services. J Clin Nurs. 2009;18(23):3225-3236.

146. Dieterich M, Irving CB, Park B, Marshall M. Intensive case management for severe mental illness. Cochrane Database Syst Rev. 2010;(10):CD007906.

147. Pitt V, Lowe D, Hill S, et al. Consumer-providers of care for adult clients of statutory mental health services. Cochrane Database Syst Rev. 2013;3:CD004807.

148. Shean GD. Empirically Based Psychosocial Therapies for Schizophrenia: The Disconnection between Science and Practice. Schizophr Res Treatment. 2013;2013:792769.

149. Archer J, Bower P, Gilbody S, et al. Collaborative care for depression and anxiety problems. Cochrane Database Syst Rev. 2012;10: CD006525.

150. Lee S, Keating C, de Castella A, Kulharni J. Fitting together the pieces: collaborative care models for adulst with severe and persistent mental illness. Camberra: National Advisory Council on Mental Health; 2010. Available from: http:/www.health.gov.au/internet/main/publishing.nsf/ Content/0ABBFD239D790377CA257BF0001C6CBC/\$File/colsev. pdf. Accessed June 24, 2013.

151. Wunderink L, Nieboer RM, Wiersma D, Sytema S, Nienhuis FJ. Recovery in remitted first-episode psychosis at 7 years of follow-up of an early dose reduction/discontinuation or maintenance treatment strategy: long-term follow-up of a 2-year randomized clinical trial. JAMA Psychiatry. 2013;70(9):913-920.

152. Agius M, Goh C, Ulhaq S, McGorry P. The staging model in schizophrenia, and its clinical implications. Psychiatr Danub. 2010;22(2):211-220.

153. Ruiz-Iriondo M, Salaberria K, Echeburúa E. Schizophrenia: analysis and psychological treatment according to the clinical staging. Actas Esp Psiquiatr. 2013;41(1):52-59.
Neuropsychiatric Disease and Treatment

\section{Publish your work in this journal}

Neuropsychiatric Disease and Treatment is an international, peerreviewed journal of clinical therapeutics and pharmacology focusing on concise rapid reporting of clinical or pre-clinical studies on a range of neuropsychiatric and neurological disorders. This journal is indexed on PubMed Central, the 'PsycINFO' database and CAS.

\section{Dovepress}

The manuscript management system is completely online and includes a very quick and fair peer-review system, which is all easy to use. Visit http://www.dovepress.com/testimonials.php to read real quotes from published authors. 